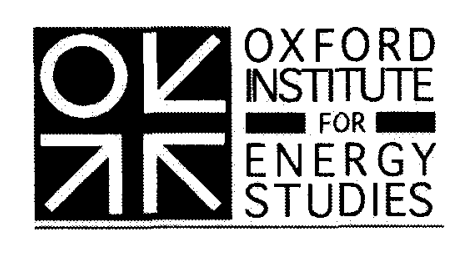

\title{
Taxation and the Optimization of Oil Exploration and Production: The UK Continental Shelf
}

Carlo A. Favero

Oxford Institute for Energy Studies

EE12

1990 
TAXATION AND THE OPTIMIZATION OF OIL EXPLORATION AND PRODUCTION:

THE UK CONTINENTAL SHELF

CARLO A. FAVERO

EE12

Oxford Institute for Energy Studies

1990 
The contents of this paper are the author's sole responsibility. They do not necessarily represent the views of the Oxford Institute for Energy studies or any of its members.

Copyright 91990

Oxford Institute for Energy Studies

ISBN $0948061 \quad 37 \quad 5$ 


\begin{abstract}
This paper allows for the effect of taxation in the econometric model for the analysis of exploration and production policies of "price taking suppliers" recently proposed in Pesaran(1990).

The tax system in the UKCS is neither neutral nor stable, therefore the separation of the "deep" parameters in the model from the tax parameters is an issue of crucial importance. The inclusion of taxation in the empirical analysis of oil exploration and extraction on the UKCS over the period 1978:1-1986:4 confirms the results obtained in the model without taxes of a zero discount factor for the producers but delivers much more plausible estimates for the marginal extraction costs.
\end{abstract}




\section{ACKNOWLEDGEMENTS}

I have greatly benefited from detailed comments by Hashem Pesaran and from discussion with Robert Mabro and Cristina Caffarra. The data-set and the econometric package Micro-Fit have been kindly provided by Hashem Pesaran. This paper is part of a research project sponsored by the Oxford Institute for Energy Studies. Partial financial support from the Newton Trust of Trinity College is gratefully acknowledged. 


\section{CONTENTS}

1. Introduction 1

2. The UKCS Oil Fiscal Regime 2

3. An Intertemporal Model Of Exploration 5

and Extraction with Taxation

4. The Empirical Results 15

$\begin{array}{ll}\text { 5. Conclusions } & 18\end{array}$

$\begin{array}{ll}\text { Tables } & 19\end{array}$

Data Appendix 21

Figures 24 


\section{INTRODUCTION}

In a recent paper $H$. Pesaran (1990) has developed an econometric model for the analysis of the exploration and extraction policies of "price taking" suppliers of oil and has applied it to the UK Continental Shelf (UKCS). The model takes explicit account of the process of oil discovery and of the intertemporal nature of the exploration and production decisions. Estimation of the model over the period 1978(1)-1986(4) produces an important trade-off between statistical fit and the plausibility of the estimates. The use of rational expectations delivers statistically significant results with estimates of the structural parameters that have the theoretically expected signs, but average marginal extraction costs over the sample take an implausibly high value of over $\$ 100$ and the "shadow price" of oil in the ground is not always positive. Sensitivity analysis reveals that one important reason for the implausibly high average estimate of the marginal extraction cost is the low estimate obtained for the intertemporal discount rate: the most plausible estimates for the marginal extraction costs are obtained by setting the discount rate to infinity, i.e. by assuming that the future is irrelevant to the exploration and production decisions of the firm. The aim of this paper is to evaluate the sensitivity of this result to the inclusion of taxation in an intertemporal model of exploration and production of North Sea oil.

The necessary conditions to omit taxation from an economic and econometric model are that the tax system is neutral and stable. A system can be considered neutral if it does not affect the decision of economic agents. A non-neutral tax system has to be explicitly modelled because, by definition, it affects firms' decisions with respect to exploration, development and production activities. A tax system is unstable if its characteristics change from those which decision-makers could have known at the time their decisions were made. Such changes should be reflected in modifications of the optimal intertemporal path of the decision variables. The first section of the paper is devoted to a description of the North Sea oil tax-system in the period $1978-86$ in order to assess its neutrality and stability. In the second section tax-dependent supply and exploration equations are derived from an intertemporal optimization framework. The third section is devoted to the estimation of a two-equation econometric model. 


\section{THE UKCS OIL FISCAL REGIME}

The United Kingdom Continental Shelf (UKCS) oil fiscal regime was introduced by the Oil Taxation Act in 1975 and operates essentially in three stages (Mabro et.al.(1986)):

- the first stage is the payment of a royalty based on the gross field revenues. The royalty can be paid in cash or in kind and it was fixed at $12.5 \%$ of the revenue over the entire sample period 1 .

- the second stage is the Petroleum Revenue Tax (PRT).

The PRT is assessed on a field by field basis : around each field a notional "ring fence" prevents external influences affecting the PRT bill paid. In practice a company has as many PRT assessments as it has shares in different fields and company losses in one field cannot be set against profit in other fields.

The PRT is assessed on total revenue, royalties and allowable expenditure plus an uplift are deductible, in addition there are an oil allowance and a safeguard. Allowable expenditure includes all the expenditure incurred in discovering a field and producing oil from it. Costs incurred in exploration and development are increased by the amount of an uplift which was originally set at $75 \%$ and reduced to $35 \%$ in 1979 ; from the start of 1981 a cut-off date is calculated as being the end of the period in which the field reaches payback (i.e. when the cumulative revenues of a field exceed the cumulative outgoings). Before 1979 the oil allowance was a deduction from profits of 500,000 tonnes of oil for each six-month period up to a cumulative maximum of 10 million tonnes, from 1979 onwards 250,000 tonnes are allowed for each period with a maximum cumulative allowance of 5 million tonnes.

The safeguard is a limitation on PRT that is restricted to be no more than the $80 \%$ of the amount by which the adjusted profits (assessable profits plus oil allowances and capital allowances) exceed $15 \%$ of the accumulated capital expenditure at the end of the period.

The PRT rate has varied considerably over the sample period, in the range $45 . \%$ $-75 \%$.(figure 1 )

Some modifications in the payment of the royalty occurred from 1983 onward but they affected only new fields. It is also difficult to model them explicitly in the case of aggregate production decisions 
With the Finance Act of 1983 relevant changes in PRT have been introduced which apply only to new projects. The ratio of the modification was to keep intact the revenues from existing fields, simultaneously offering incentives to the development of new fields. Three major changes were introduced in the taxation of new fields : the oil allowance was doubled, an exemption from the payment of royalty was fully granted, and the ring fence was partially lifted for exploration and appraisal costs incurred after March 1983. In March 1987 the Cross Field Allowance for new fields extended the facilitations to development and the development costs of a new oil field were allowed to be offset against the PRT liability on other existing fields.

The 1981 Budget introduced a Supplementary Petroleum Duty (SPD) in addition to PRT. The new tax was charged at a rate of $20 \%$ of gross production revenue from each field less an allowance of 1 million tonnes per annum. It was calculated on a field by field basis and it was deductible in calculating profits liable to both PRT and Corporation Taxes.

At the end of 1982 SPD was succeeded by the Advance Petroleum Revenue Tax (APRT) which is essentially a method of collecting PRT liability in advance. APRT was originally calculated the same way as SPD but it was not deductible before PRT and corporation taxes were calculated, although the extent to which APRT was paid had the effect of reducing subsequent PRT bills accordingly.

Also the rate of APRT varied within the sample (figure 2) and the tax was phased out from 1983 onwards. The third stage in the oil taxation system is the corporation tax (CT). CT is levied on the operating company and not on individual fields, both the royalties and the PRT are deductible from the CT. The CT rate over the sample is plotted in fig.4.

On the basis of this brief description of the UKCS tax-system we can now discuss its neutrality and stability.

As far as neutrality is concerned we notice that one of the main features of the tax-system is the lack of progressivity. The tax rates are constant, and there are very few elements of progressivity in the tax-base, the most noticeable being the oil allowance. Leaving aside equity considerations, the absence of a progressive tax system has three major implications [Clunies-Ross(1982), Hann-Rowland(1986)] 
i) for a given tax revenue target a progressive tax system is less likely to affect projects in such a way that development decisions are jeopardized: the impact of a progressive tax-system on companies earning marginal profits is negligible.

ii) a progressive tax system will not magnify the impact of other imperfections in the tax-system. The non-progressivity of the tax system will render severe a reduction of the marginal field profitability caused by a mistaken inclusion of part of the normal profits in the tax-base.

iii) a non-progressive tax-system causes higher variability of post tax profits than a progressive one. Given the variability of oil price, the risk associated with the development of marginal fields is higher when the tax-system is not progressive.

We can conclude that the lack of progressivity of the tax-system is a strong reason to consider it as non-neutral.

Another reason for non-neutrality resides in the relation between the tax-system and risk in the exploratory and development activity. Exploration and development in the North Sea are risky activities because of the possibility of drilling dry holes, the difficulty of delineate deposits, the problem of estimating reserves, and the unknown geology of the areas investigated. The ring-fence provision, which precludes setting losses in any fields against profit obtained by the same company from other fields, does not give any premium to the risk. The fact that the risk is entirely born by a risk-averse taxpayer increases the non-neutrality of the taxes.

Moving to stability, we notice immediately that the absence of progressivity is in itself a potential cause of instability of the tax-system : in fact only in a progressive tax system price rises would automatically generate an increase in tax revenue without any need for modifications of the system's rates.

The empirical evidence shows that the time span between the date of proposal and the date of implementation of modifications in the tax system ranges from a minimum of -2 months (PRT was proposed in the March 1975 budget, but put into effect from January 1975 ) to a maximum of 2 years (See Hann and Rowland[1986] pp.13-14). 
Since the development lag (the time-span between the discovery and the production start-up dates) ranges from three years and ten months to twelve years [ See Mabro et al.[1986] table S3 page 320] it follows that all the changes in the tax system must be considered as unknown at the time exploration and output decisions are taken. From figures 1-4 we can see that there has been a great deal of variation in the tax parameters, and the relevant tax parameters are not only unknown to the firm but also unpredictable, as stated earlier, to both the UK Offshore Operators Association and BRINDEX (the association of about forty smaller oil companies) (Clunies Ross[1982]).

The reason for the unpredictability is ascribed by some economists (Hann [1985]) to the fact that the reform in oil taxation is driven more by political and bureaucratic pressures than by economic factors predictable by firms.

We can therefore conclude that there is no evidence of stability and neutrality in the UKCS tax system and the inclusion of taxation in a model of exploration and production of North Sea Oil in the UKCS is a task of some relevance.

\section{AN INTERTEMPORAL MODEL OF EXPLORATION AND EXTRACTION WITH TAXATION}

To model exploration and extraction in the UKCS we assume that producers are risk neutral and decide on the rates of extraction $q_{t}, q_{t+1}, \cdots$ and the rates of exploratory efforts, $x_{t}, x_{t+1} \ldots$, by maximizing the discounted future streams of profits conditional on the information set $\Omega_{t-1}$, which includes the taxation system in force at time $t-1$. Therefore the desired values for extraction and production are found by solving the intertemporal optimization problem

$\underset{\substack{\mathrm{q}_{t}, \mathrm{q}_{\mathrm{t}+1} \cdots \\ \mathrm{x}_{\mathrm{t}}, \mathrm{x}_{\mathrm{t}+1} \cdots}}{\operatorname{Max}} \mathrm{E}\left\{{\left.\stackrel{\infty}{\Sigma} \beta^{\tau} \Pi_{\mathrm{t}+\tau} \mid \Omega_{\mathrm{t}-1}\right\}}\right\}$

where $0 \leq \beta<1$ is the discount factor and $\Pi_{t}$ is the producer profit defined as follows 
$\Pi_{\mathrm{t}}=\quad \mathrm{p}_{\mathrm{t}} \mathrm{q}_{\mathrm{t}}-\mathrm{C}\left(\mathrm{q}_{\mathrm{t}}, \mathrm{R}_{\mathrm{t}-1}\right)-\mathrm{w}_{\mathrm{t}} \mathrm{x}_{\mathrm{t}}-\left\{\left(\tau_{1 \mathrm{t}}+\tau_{4 \mathrm{t}}\right) \mathrm{p}_{\mathrm{t}} \mathrm{q}_{\mathrm{t}}+\tau_{2 \mathrm{t}}\left[\mathrm{p}_{\mathrm{t}} \mathrm{q}_{\mathrm{t}} \quad-\mathrm{C}\left(\mathrm{q}_{\mathrm{t}}, \mathrm{R}_{\mathrm{t}-1}\right)\right.\right.$

$\left.-\mathrm{up}_{\mathrm{t}} \mathrm{w}_{\mathrm{t}} \mathrm{x}_{\mathrm{t}}-\left(\tau_{1 \mathrm{t}}+\tau_{4 \mathrm{t}}\right) \mathrm{p}_{\mathrm{t}} \mathrm{q}_{\mathrm{t}}\right]+\tau_{\mathrm{ct}}\left[\mathrm{p}_{\mathrm{t}} \mathrm{q}_{\mathrm{t}}-\left(\tau_{1 \mathrm{t}}+\tau_{4 \mathrm{t}}\right) \mathrm{p}_{\mathrm{t}} \mathrm{q}_{\mathrm{t}}-\tau_{2 \mathrm{t}}\left[\mathrm{p}_{\mathrm{t}} \mathrm{q}_{\mathrm{t}}-\mathrm{C}\left(\mathrm{q}_{\mathrm{t}}, \mathrm{R}_{\mathrm{t}-1}\right)-\mathrm{up}_{\mathrm{t}} \mathrm{w}_{\mathrm{t}} \mathrm{x}_{\mathrm{t}}\right.\right.$ $\left.\left.-\left(\tau_{1 \mathrm{t}}+\tau_{4 \mathrm{t}}\right) \mathrm{p}_{\mathrm{t}} \mathrm{q}_{\mathrm{t}}\right]\right\}$

which can be rewritten as

$\Pi_{t}=\alpha_{1 t} p_{t} q_{t}-\alpha_{2 t} C\left(q_{t}, R_{t-1}\right)-\alpha_{3 t} w_{t} x_{t}$

where

$\alpha_{1 \mathrm{t}}=\left\{1-\left(\tau_{1 \mathrm{t}}+\tau_{4 \mathrm{t}}\right)-\tau_{2 \mathrm{t}}\left[1-\left(\tau_{1 \mathrm{t}}+\tau_{4 \mathrm{t}}\right)\right]-\tau_{\mathrm{ct}}\left[1-\left(\tau_{1 \mathrm{t}}+\tau_{4 \mathrm{t}}\right)-\tau_{2 \mathrm{t}}\left[1-\left(\tau_{1 \mathrm{t}}+\tau_{4 \mathrm{t}}\right)\right]\right\}\right.$

$\alpha_{2 \mathrm{t}}=\left[1-\tau_{2 \mathrm{t}}-\tau_{\mathrm{ct}} \tau_{2 \mathrm{t}}\right]$

$\alpha_{3 \mathrm{t}}=\left[1-\tau, \mathrm{te}_{\mathrm{t}} \mathrm{up}_{\mathrm{ct}}-\tau_{2 \mathrm{t}} \mathrm{up}_{\mathrm{t}}\right]$

$q_{t}$ : rate of extraction

$R_{t}$ : level of proven reserves

$x_{t}$ : rate of exploratory effort

$\mathbf{p}_{t}$ : well-head price

$w_{t}$ : unit cost of exploratory effort

$\tau_{2 t}:$ Petroleum Revenue Tax

$\tau_{1 \mathrm{t}}:$ royalty

$\tau_{3 t}:$ Advance Petroleum Revenue Tax

$\tau_{\text {ct }}$ : Corporation Tax

$u_{t}: 1+$ uplift on exploration costs

$\tau_{4 t}:$ Supplementary Petroleum Duty

Several comments on the profit function are in order.

The proposed parameterization of the function is a general specification which embeds all the features of the tax system in the sample period. The switches from one regime to the other are captured by the tax parameters, which can be considered as dummies set to zero when the tax is not applied and set to the appropriate value when the tax is charged.

In the net profit function (2)

$\left[p_{t} q_{t}-C\left(q_{t}, R_{t-1}\right)-w_{t} x_{t}\right]$ is the profit before taxes, $C\left(q_{t}, R_{t-1}\right)$ is a convex function capturing the cost of development and extraction. $C\left(q_{t}, R_{t-1}\right)$ varies positively with the rate of extraction and negatively with the level of remaining proven reserves2.

$\left(\tau_{1 \mathrm{t}}+\tau_{4 \mathrm{t}}\right) \mathrm{p}_{\mathrm{t}} \mathrm{q}_{\mathrm{t}}$ captures the effect of the royalty payment and of the SPD (when the SPD is on), which are both levied on the gross field revenues and represents the first stage of the Oil Taxation System (OTS) previously discussed.

2The inclusion of $R_{t-1}$ is justified by Pesaran(1990) on the basis of the engineering information on the determinants of the pressure dynamics of the petroleum reserves 
The second stage of the OTS is captured by the following expression

$\tau_{2 t}\left[p_{t} q_{t}-C\left(q_{t}, R_{t-1}\right)-u_{t} w_{t} x_{t}-\left(\tau_{1 t}+\tau_{4 t}\right) p_{t} q_{t}\right]$

which represents the PRT bill : royalties and SPD are deduced from gross revenues together with production costs and exploration costs augmented by the uplift.

Finally, in the third stage of the OTS, the Corporation Tax is assessed as follows

$\tau_{c t}\left[p_{t} q_{t}-\left(\tau_{1 t}+\tau_{4 t}\right) p_{t} q_{t}-\tau_{2 t}\left[p_{t} q_{t}-C\left(q_{t}, R_{t-1}\right)-u_{t} w_{t} x_{t}-\left(\tau_{1 t}+\tau_{4 t}\right) p_{t} q_{t}\right]\right.$

payments for SPD, royalties and PRT are deduced from taxable profits to determine the corporation tax bill. We notice that, since APRT it is a way of collecting PRT in advance, its effect is captured by the PRT parameter. Lastly it has to be said that the aggregate nature of the data does not allow the consideration of field allowances, whose effect can be included only when a field by field disaggregation is implemented.

To summarize we can state that the impact of the tax system in our model is captured by the three variables $\alpha_{1 t}, \alpha_{2 t}, \alpha_{3 t}$, where $\alpha_{1 \mathrm{t}}$ is a measure of the reduction in the marginal revenue due to taxation (the smaller $\alpha_{1 \mathrm{t}}$ the larger the difference between pre-tax and post-tax revenue), while $\alpha_{2 t}$ and $\alpha_{3 \mathrm{t}}$ are measures of the reduction in the marginal extraction cost and in the marginal exploration cost due to allowances in the tax system (the smaller $\alpha_{2 \mathrm{t}}$ and $\alpha_{3 \mathrm{t}}$ the higher the allowance). By plotting $\alpha_{1 \mathrm{t}}, \alpha_{2 \mathrm{t}}, \alpha_{3 \mathrm{t}}$ over the sample period (fig.5) we notice immediately a turning point in 1983, in fact from 1983 onward the wedge between pre-tax profits and post-tax profits has been decreasing uniformly.

In optimizing the firm faces the following constraints:

$\mathrm{R}_{\mathrm{t}+\tau}-\mathrm{R}_{\mathrm{t}+\tau-1}=\mathrm{d}_{\mathrm{t}+\tau}+\mathrm{e}_{\mathrm{t}+\tau}-\mathrm{q}_{\mathrm{t}+\tau} \quad \tau=0,1,2, .$.

$\mathrm{x}_{\mathrm{t}}=\mathrm{x}_{\mathrm{t}-1}+\mathrm{x}_{\mathrm{t}}$

where $d_{t}$ denotes the addition to proven reserves during period $t-1$ to $t$ from new discoveries, and $e_{t}$ the revisions/extensions to previously discovered reserves, $x_{t}$ represents the level of cumulative exploratory effort at time $t$. To determine $d_{t}$. we follow, as in Pesaran(1990), a version of the Kaufman(1975) model and specify that

$\mathrm{d}_{\mathrm{t}}=\mathrm{F}\left(\mathrm{x}_{\mathrm{t}}, \mathrm{X}_{\mathrm{t}-1}\right) \mu_{\mathrm{t}}$

where $\mu_{\mathrm{t}}$ is assumed to satisfy the orthogonality condition 
$\mathrm{E}\left(\mu_{\mathrm{t}} \mid \Omega_{\mathrm{t}-1}\right)=0$

The information set at time $t-1$ is assumed to contain observations on at least the current and past values of $q, x$ and past values of $R, w, p$ and all the tax parameters.

The following conditions are satisfied :

$\partial \mathrm{F}_{\mathrm{t}} / \partial \mathrm{x}_{\mathrm{t}}>0, \frac{\partial^{2} \mathrm{~F}_{\mathrm{t}}}{\partial \mathrm{x}_{\mathrm{t}}^{2}}<0, \partial \mathrm{F}_{\mathrm{t}} / \partial \mathrm{x}_{\mathrm{t}-1}<0$ for $\mathrm{t}>\mathrm{m}, \underset{\mathrm{X}_{\mathrm{t}-1} \rightarrow \infty}{\lim } \mathrm{F}\left(\mathrm{x}_{\mathrm{t}}, \mathrm{X}_{\mathrm{t}-1}\right)=0$

Therefore the marginal product of exploratory effort should be positive but diminishing, and there is a discovery decline phenomenon: as exploration proceeds the effects of reserves exhaustion dominates the influence of the accumulation of geological knowledge.

\subsection{The Euler Equations}

Given price cost and tax parameter expectations $\mathrm{p}_{\mathrm{t}+\mathrm{k}}^{\mathrm{e}}=\mathrm{E}\left(\mathrm{p}_{\mathrm{t}+\mathrm{k}} \mid \Omega_{\mathrm{t}-1}\right), \mathrm{w}_{\mathrm{t}+\mathrm{k}}^{\mathrm{e}}=$ $\mathrm{E}\left(\mathrm{w}_{\mathrm{t}+\mathrm{k}} \mid \Omega_{\mathrm{t}-1}\right), \tau_{\mathrm{i}, \mathrm{t}+\mathrm{k}}^{\mathrm{e}}=\mathrm{E}\left(\tau_{\mathrm{i}, \mathrm{t}+\mathrm{k}} \mid \Omega_{\mathrm{t}-1}\right)$, and an initial level of proven reserves the above relations completely define the decision environment of the firm.

The First Order Conditions (F.O.C.) for optimality can be obtained from unconstrained optimization of the following Lagrangean function

$L=E\left(\sum_{k=0}^{\infty} \beta^{k} G_{t+k} \mid \Omega_{t-1}\right)$

with respect to $q_{t+k}, x_{t+k}, R_{t+k}, X_{t+k} k=0,1,2 \ldots$ where

$G_{t}=\Pi_{t}+\lambda_{t}\left(d_{t}+e_{t}-q_{t}-R_{t}+R_{t-1}\right)+\mu_{t}\left(X_{t}-X_{t-1}-x_{t}\right)$

the auxiliary variables $\lambda_{t}$ and $\mu_{t}$ are the Lagrange multipliers.

The F.O.C. for maximization can be written as follows ${ }^{3}$

$\mathrm{E}_{\mathrm{t}-1}\left(\alpha_{1 \mathrm{t}} \mathrm{p}_{\mathrm{t}+\tau}-\alpha_{2 \mathrm{t}} \frac{\partial \mathrm{C}_{\mathrm{t}+\tau}}{\partial \mathrm{q}_{\mathrm{t}+\tau}}-\lambda_{\mathrm{t}+\tau}\right)=0$

$\mathbf{E}_{\mathrm{t}-1}\left(\beta \lambda_{\mathrm{t}+\tau+1}-\lambda_{\mathrm{t}+\tau}-\alpha_{2 \mathrm{t}} \beta \frac{\partial \mathrm{C}_{\mathrm{t}+\tau+1}}{\partial \mathrm{R}_{\mathrm{t}+\tau}}\right)=0$

$\mathrm{E}_{\mathrm{t}-1}\left(\mu_{\mathrm{t}+\tau}+\alpha_{3 \mathrm{t}} \mathrm{w}_{\mathrm{t}+\tau}-\lambda_{\mathrm{t}+\tau} \frac{\partial \mathrm{d} \mathrm{t}+\tau}{\partial \mathrm{x}_{\mathrm{t}+\tau}}\right)=0$

${ }^{3}$ The transversality conditions relevant to this optimization are assumed to be satisfied 


$$
\begin{aligned}
& \mathrm{E}_{\mathrm{t}-1}\left(\mu_{\mathrm{t}+\tau}-\beta \mu_{\mathrm{t}+\tau+1}+\beta \lambda_{\mathrm{t}+\tau+1} \frac{\partial \mathrm{d}_{\mathrm{t}+\tau+1}}{\partial \mathrm{X}_{\mathrm{t}+\tau}}\right)=0 \\
& \mathrm{E}_{\mathrm{t}-1}\left(\mathrm{R}_{\mathrm{t}+\tau}-\mathrm{R}_{\mathrm{t}+\tau-1}-\mathrm{d}_{\mathrm{t}+\tau}-\mathrm{e}_{\mathrm{t}+\tau}+\mathrm{q}_{\mathrm{t}+\tau}\right)=0 \\
& \mathrm{E}_{\mathrm{t}-1}\left(\mathrm{X}_{\mathrm{t}+\tau}-\mathrm{X}_{\mathrm{t}+\tau+1}-\mathrm{x}_{\mathrm{t}+\tau}\right)=0
\end{aligned}
$$

From this set of equations we can interpret economically the two Lagrange multipliers $\lambda_{t}$ and $\mu_{\mathrm{t}}: \lambda_{\mathrm{t}}$ represents the net of tax shadow price of reserves in the ground, while $\mu_{\mathrm{t}}$ can be interpreted as the net value of the marginal product of reserves discovery (See Pesaran(1990).

Conditions (8a) $-(8 f)$ are non linear but they can be transformed to derive exploration and extraction rules that can be consistently estimated. If we focus on current decision variables $\mathrm{q}_{\mathrm{t}}$ and $\mathrm{x}_{\mathrm{t}}$ and rewrite relations (8a) $-(8 \mathrm{f})$ for $\tau=0$ we have

$$
\begin{aligned}
& \mathrm{E}_{\mathrm{t}-1}\left(\lambda_{\mathrm{t}}\right)=\mathrm{E}_{\mathrm{t}-1}\left(\alpha_{1 \mathrm{t}} \mathrm{p}_{\mathrm{t}}-\alpha_{2 \mathrm{t}} \frac{\partial \mathrm{C}_{\mathrm{t}}}{\partial \mathrm{q}_{\mathrm{t}}}\right) \\
& \mathrm{E}_{\mathrm{t}-1}\left(\lambda_{\mathrm{t}}\right)=\beta \mathrm{E}_{\mathrm{t}-1}\left(\lambda_{\mathrm{t}+1}-\alpha_{2 \mathrm{t}} \frac{\partial \mathrm{C}_{\mathrm{t}+1}}{\partial \mathrm{R}_{\mathrm{t}}}\right) \\
& \mathrm{E}_{\mathrm{t}-1}\left(\mu_{\mathrm{t}}\right)=\mathrm{E}_{\mathrm{t}-1}\left(\lambda_{\mathrm{t}} \frac{\partial \mathrm{d}_{\mathrm{t}}}{\partial \mathrm{x}_{\mathrm{t}}}-\alpha_{3} \mathrm{w}_{\mathrm{t}}\right) \\
& \mathrm{E}_{\mathrm{t}-1}\left(\mu_{\mathrm{t}}\right)=\beta \mathrm{E}_{\mathrm{t}-1}\left(\mu_{\mathrm{t}+1}-\lambda_{\mathrm{t}+1} \frac{\partial \mathrm{d}_{\mathrm{t}+1}}{\partial \mathrm{X}_{\mathrm{t}}}\right)
\end{aligned}
$$

Equation (9a) gives an expression for the expected shadow price of oil in the ground; it is noticeable that both the expected well-head price and the expected marginal extraction cost are affected by the tax system. Equation (9b) gives the intertemporal condition for the extraction of oil over time. Equations (9c) and (9d) give the necessary conditions for the determination of the optimum level of exploration. Again it is noticeable that the expected return from exploration, defined by the right hand side of $(9 \mathrm{c})$ is affected by the tax system.

\section{a)The Production equation}

We can derive an output equation from condition (9a)-(9d) by eliminating all the unobservables.

From (9a) we have 
$\mathrm{E}_{\mathrm{t}-1}\left(\lambda_{\mathrm{t}+1}\right)=\mathrm{E}_{\mathrm{t}-1}\left(\mathrm{E}_{\mathrm{t}} \alpha_{1 \mathrm{t}+1} \mathrm{p}_{\mathrm{t}+1}-\mathrm{E}_{\mathrm{t}} \alpha_{2 \mathrm{t}+1} \frac{\partial \mathrm{C}_{\mathrm{t}+1}}{\partial \mathrm{q}_{\mathrm{t}+1}}\right)$

and, assuming expectations are formed consistently yields

$\mathrm{E}_{\mathrm{t}-1}\left(\lambda_{\mathrm{t}+1}\right)=\mathrm{E}_{\mathrm{t}-1}\left(\alpha_{1 \mathrm{t}+1} \mathrm{p}_{\mathrm{t}+1}-\alpha_{2 \mathrm{t}+1} \frac{\partial \mathrm{C}_{\mathrm{t}+1}}{\partial \mathrm{q}_{\mathrm{t}+1}}\right)$

Substituting this result in (9b) and using (9a) to eliminate $\mathrm{E}_{t-1}\left(\lambda_{t}\right)$, we obtain

$\mathrm{E}_{\mathrm{t}-1}\left(\frac{\partial \mathrm{C}_{\mathrm{t}}}{\partial \mathrm{q}_{\mathrm{t}}}\right)=\mathrm{E}_{\mathrm{t}-1}\left[\left(\alpha_{1 \mathrm{t}} / \alpha_{2 \mathrm{t}}\right)\left(\mathrm{p}_{\mathrm{t}}-\beta \mathrm{p}_{\mathrm{t}+1}\right)+\beta \mathrm{E}_{\mathrm{t}-1}\left(\frac{\partial \mathrm{C}_{\mathrm{t}+1}}{\partial \mathrm{q}_{\mathrm{t}+1}}+\frac{\partial \mathrm{C}_{\mathrm{t}}}{\partial \mathrm{q}_{\mathrm{t}}}\right)\right.$

This equation does not depend on the Lagrange multipliers and, for a given specification of the extraction cost function, it can be consistently estimated.

The following non-linear form[Pesaran(1990)] for the extraction cost function is adopted

$\mathrm{C}\left(\mathrm{q}_{\mathrm{t}}, \mathrm{R}_{\mathrm{t}-1}\right)=\delta_{0}+\delta_{1} \mathrm{q}_{\mathrm{t}}+{ }_{2}^{1}\left(\delta_{2}+{ }_{\mathrm{R}} \mathrm{R}_{\mathrm{t}-1}\right) \mathrm{q}_{\mathrm{t}}^{2}+\epsilon_{\mathrm{t}} \mathrm{q}_{\mathrm{t}}$

where $\epsilon_{t}$ represents unobserved random shocks to marginal extraction cost, which are assumed to be orthogonal to the information set $\Omega_{t-1}$, all the parameters in the cost function are expected to be positive except for $\delta_{1}$ which could be negative so long as $\mathrm{E}_{\mathrm{t}-1}\left(\partial \mathrm{C}_{\mathrm{t}} / \partial \mathrm{q}_{\mathrm{t}}\right)>0$.

Using (12) we arrive at the following specification for the optimal level of extraction $q_{t}^{*}$,

$\delta_{1}+{ }_{\mathrm{z}_{\mathrm{t}-1}}^{\delta_{2} \mathrm{q}_{\mathrm{t}}^{*}}=\mathrm{E}_{\mathrm{t}-1}\left[\left(\alpha_{1 \mathrm{t}} / \alpha_{2 \mathrm{t}}\right) \mathrm{p}_{\mathrm{t}}-\beta \frac{\left.{ }^{\alpha}{ }_{1 \mathrm{t}+1} \mathrm{p}_{\mathrm{t}+1}\right)}{\alpha_{2 \mathrm{t}}}+\frac{\beta_{2 \mathrm{t}+1}^{\alpha_{2}}}{\alpha_{2 \mathrm{t}}}\left(\delta_{1}+\mathrm{q}_{\mathrm{t}+1} \mathrm{z}_{\mathrm{t}}-\frac{1}{2}\right.\right.$

$\left.\delta_{3} \frac{\mathrm{q}_{\mathrm{t}+1}^{2}}{\mathbf{R}_{\mathrm{t}}^{2}}\right]$

$\mathbf{z}_{\mathrm{t}}=\frac{\mathbf{R}_{\mathrm{t}}}{\mathbf{R}_{\mathrm{t}}+\gamma} \quad \gamma=\delta_{3} / \delta_{2} \geq 0$

This result generalizes equation (13) in Pesaran(1990) to give the desired level of output as a function of reserves, price expectations and firm's planned or expected future output and reserves, and the expected level and the change in future tax parameters. We can rewrite (13) as 


$$
\begin{aligned}
& \mathrm{q}_{\mathrm{t}}^{*}\left.=\left(\delta_{1} / \delta_{2}\right) \mathrm{E}_{\mathrm{t}-1} \frac{\beta{ }^{\alpha} \mathrm{t}+1}{\alpha{ }_{2 \mathrm{t}}} \mathrm{z}_{\mathrm{t}-1}\right]-\left(\delta_{1} / \delta_{2}\right) \mathrm{z}_{\mathrm{t}-1}+\delta_{2}^{-1} \mathrm{z}_{\mathrm{t}-1} \mathrm{E}_{\mathrm{t}-1}\left[\left(\alpha_{1 \mathrm{t}} / \alpha_{2 \mathrm{t}}\right) \mathrm{p}_{\mathrm{t}}\right] \\
&-\delta_{2}{ }^{1} \mathrm{z}_{\mathrm{t}-1} \mathrm{E}_{\mathrm{t}-1}\left[\frac{\beta{ }^{\alpha} 1 \mathrm{t}+1}{\alpha_{2 \mathrm{t}}} \mathrm{p}_{\mathrm{t}+1}\right]+ \\
& \beta \mathrm{z}_{\mathrm{t}-1} \mathrm{E}_{\mathrm{t}-1}\left(\frac{{ }^{\alpha} \mathrm{t}+1}{\alpha} \mathrm{q}_{\mathrm{t}+1}\right)+\beta \mathrm{z}_{\mathrm{t}-1} \mathrm{E}_{\mathrm{t}-1}\left(\frac{\left.\alpha_{2 \mathrm{t}+1} \mathrm{~h}_{\mathrm{t}+1}\right)}{\alpha_{2 \mathrm{t}}}\right)
\end{aligned}
$$

Notice that equation (14) depends on the ratios $\alpha_{1 \mathrm{t}} / \alpha_{2 \mathrm{t}}, \alpha_{1 \mathrm{t}+1} / \alpha_{2 \mathrm{t}}$ and $\alpha_{2 \mathrm{t}+1} / \alpha_{2 \mathrm{t}}$, suggesting that the omission of the tax system is going to affect the econometric performance of the model unless the ratios are constant over time. Figures $6.1-6.3$ report the variation over the sample 1978:1-1986:4 of the relevant tax variables $\alpha_{1 \mathrm{t}} / \alpha_{2 \mathrm{t}}$.

By assuming that the relationship between the actual rate of extraction and the firm's desired rate of extraction can be characterized by the following simple partial adjus tment model

$\mathrm{q}_{\mathrm{t}}-\mathrm{q}_{\mathrm{t}-1}=\varphi\left(\mathrm{q}_{\mathrm{t}}^{*}-\mathrm{q}_{\mathrm{t}-1}\right)$

we have

$\mathrm{q}_{\mathrm{t}}=(1-\varphi) \mathrm{q}_{\mathrm{t}-1}+\mathrm{b}_{0} \mathrm{z}_{\mathrm{t}-1} \mathrm{E}_{\mathrm{t}-1}\left[\frac{\alpha_{2 \mathrm{t}+1}}{\alpha_{2 \mathrm{t}}}\right]+\mathrm{b}_{1} \mathrm{z}_{\mathrm{t}-1}+\mathrm{b}_{2} \mathrm{z}_{\mathrm{t}-1} \mathrm{E}_{\mathrm{t}-1}\left[\left(\alpha_{1 \mathrm{t}} / \alpha_{2 \mathrm{t}}\right) \mathrm{p}_{\mathrm{t}}-\right.$ $\left.\frac{\beta \alpha_{1 \mathrm{t}+1}}{\alpha_{2 \mathrm{t}}} \mathrm{p}_{\mathrm{t}+1}\right]+\mathrm{b}_{3} \mathrm{z}_{\mathrm{t}-1} \mathrm{E}_{\mathrm{t}-1}\left(\frac{\alpha_{2 \mathrm{t}+1}}{\alpha_{2 \mathrm{t}}} \mathrm{q}_{\mathrm{t}+1}\right)+\mathrm{b}_{4} \mathrm{z}_{\mathrm{t}-1} \mathrm{E}_{\mathrm{t}-1}\left(\frac{\left.\alpha_{2 \mathrm{t}+1} \mathrm{~h}_{\mathrm{t}+1}\right)}{\alpha_{2 \mathrm{t}}}\right)$

where

$\mathrm{b}_{0}=\varphi \beta \delta_{1} / \delta_{2} ; \mathrm{b}_{1}=-\varphi \delta_{1} / \delta_{2} \leq 0$

$\left.\mathrm{b}_{2}=\varphi \delta_{2}^{-1} \geq 0 ; \mathrm{b}_{3}=\varphi \beta \geq 0 \quad \mathrm{~b}_{4}=\varphi \beta \gamma \geq\right)$

To model oil prices expectations and tax parameters' expectations we consider two alternative hypotheses. Under the first hypothesis expectations on both tax parameters and oil price are assumed to be rational and we have

$$
\begin{aligned}
& \mathrm{E}_{\mathrm{t}-1} \mathrm{p}_{\mathrm{t}}=\mathrm{p}_{\mathrm{t}}+\xi_{1 \mathrm{t}} \\
& \mathrm{E}_{\mathrm{t}-1} \mathrm{p}_{\mathrm{t}+1}=\mathrm{p}_{\mathrm{t}+1}+\xi_{1 \mathrm{t}+1} \\
& \mathrm{E}_{\mathrm{t}-1} \alpha_{\mathrm{it}}=\alpha_{\mathrm{it}}+\xi_{\mathrm{it}}^{\alpha} \\
& \mathrm{E}_{\mathrm{t}-1} \alpha_{\mathrm{it}+1}=\alpha_{\mathrm{it}}+\xi_{\mathrm{it}+1}^{\alpha}
\end{aligned}
$$


where $\xi_{i t+k}$ satisfies the orthogonality property $E\left(\xi_{i t+k} \mid \Omega_{t-1}\right)=0$

We notice that, although the changes in the tax parameters are usually announced in the Budget, we still mantain the possibility of forecasting errors in predicting future tax parameters, generated by the length of the development lag.

Our second alternative for expectations formation is constituted by an adaptive expectations scheme for price combined with a rational expectations scheme for the tax parameters.

We have

$\mathrm{E}_{\mathrm{t}-1} \mathrm{p}_{\mathrm{t}}=\mathrm{E}_{\mathrm{t}-1} \mathrm{p}_{\mathrm{t}+1}=(1-\theta) \sum_{\mathrm{i}=1}^{\infty} \theta^{\mathrm{j}-1} \mathrm{p}_{\mathrm{t}-\mathrm{i}}=\tilde{\mathrm{p}}(\theta)$ where $0 \leq \theta<1$

$\mathrm{E}_{\mathrm{t}-1} \alpha_{\mathrm{it}}=\alpha_{\mathrm{it}}+\xi_{\mathrm{it}}^{\alpha}$

$\mathrm{E}_{\mathrm{t}-1} \alpha_{\mathrm{it}+1}=\alpha_{\mathrm{it}}+\xi_{\mathrm{it}+1}^{\alpha}$

under this alternative we consider the possibility of a backward looking behaviour by agents in the formation of price expectations, possibly justified by the high volatility of oil prices within the sample period. However we do not remove the hypothesis of rational expectations on the tax parameters because the relaxations of this hypothesis would have the implication that announcements made at time $t-1$ of future modifications in the tax parameters are ignored by the representative firm.

Summarizing, we will consider the two following empirical alternatives for the supply equation

(i) Rational Expectations model

$q_{t}=(1-\varphi) q_{t-1}+b_{0} z_{t-1}\left[\frac{\alpha_{2 t+1}}{\alpha_{2 t}}\right]+b_{1} z_{t-1}+b_{2} z_{t-1}\left[\left(\alpha_{1 t} / \alpha_{2 t}\right) p_{t}-\frac{\beta \alpha_{1 t+1}}{\alpha_{2 t}}\right.$

$\left.\mathrm{p}_{\mathrm{t}+1}\right]+\mathrm{b}_{3} \mathrm{z}_{\mathrm{t}-1}\left(\frac{\alpha_{2 \mathrm{t}+1}}{\alpha_{2 \mathrm{t}}} \mathrm{q}_{\mathrm{t}+1}\right)+\mathrm{b}_{4} \mathrm{z}_{\mathrm{t}-1}\left(\frac{\alpha_{2 \mathrm{t}+1}}{\alpha_{2 \mathrm{t}}} \mathrm{h}_{\mathrm{t}+1}\right)+\epsilon_{1 \mathrm{t}}$

where 


$$
\begin{aligned}
& \epsilon_{1 \mathrm{t}}=\mathrm{b}_{0^{\mathrm{t}-1}}\left[\mathrm{E}_{\mathrm{t}-1}\left(\frac{\alpha_{2 \mathrm{t}+1}}{\alpha_{2 \mathrm{t}}}\right)-\left(\frac{\alpha_{2 \mathrm{t}+1}}{\alpha_{2 \mathrm{t}}}\right)\right]+\mathrm{b}_{2} \mathrm{z}_{\mathrm{t}-1}\left\{\mathrm { E } _ { \mathrm { t } - 1 } \left[\left(\alpha_{1 \mathrm{t}} / \alpha_{2 \mathrm{t}}\right) \mathrm{p}_{\mathrm{t}}-\right.\right. \\
& \left.\left.\frac{\beta \alpha_{1 \mathrm{t}+1}}{\alpha_{2 \mathrm{t}}} \mathrm{p}_{\mathrm{t}+1}\right]-\left(\alpha_{1 \mathrm{t}} / \alpha_{2 \mathrm{t}}\right) \mathrm{p}_{\mathrm{t}}+\frac{\beta \alpha_{1 \mathrm{t}+1}}{\alpha_{2 \mathrm{t}}} \mathrm{p}_{\mathrm{t}+1}\right\}+\mathrm{b}_{3} \mathrm{z}_{\mathrm{t}-1}\left\{\mathrm{E}_{\mathrm{t}-1}\left(\frac{\left.\alpha_{2 \mathrm{t}+1} \mathrm{q}_{\mathrm{t}+1}\right)}{\alpha_{2 \mathrm{t}}}\right)\right. \\
& \left.-\frac{{ }^{\alpha} 2 \mathrm{t}+1}{\alpha_{2 \mathrm{t}}} \mathrm{q}_{\mathrm{t}+1}\right\}++\mathrm{b}_{4} \mathrm{z}_{\mathrm{t}-1}\left\{\mathrm{E}_{\mathrm{t}-1}\left(\frac{\alpha_{2 \mathrm{t}+1}}{\alpha_{2 \mathrm{t}}} \mathrm{h}_{\mathrm{t}+1}\right)-\frac{\left.\alpha_{2 \mathrm{t}+1} \mathrm{~h}_{\mathrm{t}+1}\right\}}{\alpha_{2 \mathrm{t}}}\right.
\end{aligned}
$$

satisfies the orthogonality conditions $E\left(\epsilon_{1 t} \mid \Omega_{t-1}\right)=0$.

(ii) Mixed Adaptive and Rational Expectations model

$$
\begin{aligned}
& \mathrm{q}_{\mathrm{t}}=(1-\varphi) \mathrm{q}_{\mathrm{t}-1}+\mathrm{b}_{0} \mathrm{z}_{\mathrm{t}-1}\left[\frac{\alpha_{2 \mathrm{t}+1}}{\alpha_{2 \mathrm{t}}}\right]+\mathrm{b}_{1} \mathrm{z}_{\mathrm{t}-1}+\mathrm{b}_{2} \mathrm{z}_{\mathrm{t}-1}\left[\left(\alpha_{1 \mathrm{t}} / \alpha_{2 \mathrm{t}}\right) \tilde{\mathrm{p}}(\theta)-\frac{\beta \alpha_{1 \mathrm{t}+1}}{\alpha_{2 \mathrm{t}}}\right. \\
& \tilde{\mathrm{p}}(\theta)]+\mathrm{b}_{3} \mathrm{z}_{\mathrm{t}-1}\left(\frac{\alpha_{2 \mathrm{t}+1}}{\alpha_{2 \mathrm{t}}} \mathrm{q}_{\mathrm{t}+1}\right)+\mathrm{b}_{4} \mathrm{z}_{\mathrm{t}-1}\left(\frac{\alpha_{2 \mathrm{t}+1}}{\alpha_{2 \mathrm{t}}} \mathrm{h}_{\mathrm{t}+1}\right)+\epsilon_{2 \mathrm{t}}
\end{aligned}
$$

where

$$
\begin{aligned}
& \epsilon_{2 \mathrm{t}}=\mathrm{b}_{0} \mathrm{z}_{\mathrm{t}-1}\left[\mathrm{E}_{\mathrm{t}-1}\left(\frac{\alpha_{2 \mathrm{t}+1}}{\alpha_{2 \mathrm{t}}}\right)-\left(\frac{\alpha_{2 \mathrm{t}+1}}{\alpha_{2 \mathrm{t}}}\right)\right]+\mathrm{b}_{2 \mathrm{z}_{\mathrm{t}-1}}\left\{\mathrm { E } _ { \mathrm { t } - 1 } \left[\left(\alpha_{1 \mathrm{t}} / \alpha_{2 \mathrm{t}}\right) \tilde{\mathrm{p}}(\theta)-\right.\right. \\
& \left.\left.\frac{\beta \alpha_{1 \mathrm{t}+1}}{\alpha_{2 \mathrm{t}}} \tilde{\mathrm{p}}(\theta)\right]-\left(\alpha_{1 \mathrm{t}} / \alpha_{2 \mathrm{t}}\right) \tilde{\mathrm{p}}(\theta)+\frac{\beta \alpha_{1 \mathrm{t}+1}}{\alpha_{2 \mathrm{t}}} \tilde{\mathrm{p}}(\theta)\right\}+ \\
& \mathrm{b}_{3} \mathrm{z}_{\mathrm{t}-1}\left\{\mathrm{E}_{\mathrm{t}-1}\left(\frac{\alpha_{2 t+1}}{\alpha_{2 \mathrm{t}}} \mathrm{q}_{\mathrm{t}+1}\right)-\frac{{ }^{\alpha} \mathrm{t}+1}{\alpha_{2 \mathrm{t}}} \mathrm{q}_{\mathrm{t}+1}\right\} \\
& +b_{4} z_{t-1}\left\{E_{t-1}\left(\frac{{ }^{\alpha} 2 t+1}{\alpha_{2 t}} h_{t+1}\right)-\frac{{ }^{\alpha} 2 t+1}{\alpha_{2 t}} h_{t+1}\right\} \\
& \mathrm{E}\left(\epsilon_{2 \mathrm{t}} \mid \Omega_{\mathrm{t}-1}\right)=0
\end{aligned}
$$

As far as estimation is concerned we notice that both $\epsilon_{1 \mathrm{t}}$ and $\epsilon_{2 \mathrm{t}}$ are orthogonal to the information set $\Omega_{t-1}$, equations (16) and (17) can be therefore consistently estimated by implementing the "Error in variables" method [McCallum(1976)] using instruments dated t-2 or earlier, assuming, of course, that the parameters are in fact identified. 


\section{b) The Exploration Equation}

The first step to generate an estimable exploration equation is to combine (9c) and (9d) in the following condition

$$
E_{t-1}\left(\lambda_{t} \frac{\partial d_{t}}{\partial x_{t}}\right)=E_{t-1}\left(\alpha_{3 t_{t} w_{t}}\right)-\beta E_{t-1}\left(\alpha_{3 t+1} w_{t+1}-\lambda_{t+1}\left(\frac{\partial d_{t+1}}{\partial x_{t+1}}-\frac{\partial d_{t+1}}{\partial X_{t}}\right)\right)
$$

Then we assume that the discovery function takes the form advocated by Uhler (1976 p.79) in his empirical analysis of oil and gas discovery in the province of Alberta

$\mathrm{F}\left(\mathrm{x}_{\mathrm{t}}, \mathrm{X}_{\mathrm{t}-1}\right)=A \mathrm{x}_{\mathrm{t}}^{\rho} \exp \left(\mathrm{b}_{1} \mathrm{X}_{\mathrm{t}-1}-\mathrm{b}_{2} \mathrm{X}_{\mathrm{t}-1}^{2}\right)$

for positive values of $A, b_{1}$ and $b_{2}$ and for $0<\rho<1$ the function satisfies all the required properties, in particular the threshold value for the cumulative exploratory effort, after which we have the discovery decline phenomenon, is given by $X_{m}=b_{1} / 2 b_{2}$.

Even a discovery function like (18) produces a highly non linear functional form in the general case. However if we focus on the simple case $\beta=0$ we have the following relation for the desired rate of exploration

$$
\begin{aligned}
& \log x_{t}^{*}=d_{0}+d_{1} x_{t-1}+d_{2} x_{t-1}^{2}+d_{3} \log \left(E_{t-1} \lambda_{t} / E_{t-1} w_{t} \alpha_{3 t}\right) \\
& \text { where } d_{0}=(1-\rho)^{-1} \log (A \rho) \quad d_{1}=(1-\rho)^{-1} b_{1} \geq 0 \\
& \qquad d_{2}=(1-\rho)^{-1} b_{2}<0 \quad d_{3}=(1-\rho)^{-1}>0
\end{aligned}
$$

using again a partial adjustment mechanism, this time on the logs, we have $\log \mathrm{x}_{\mathrm{t}}=(1-\varphi) \log \mathrm{x}_{\mathrm{t}-1}+\varphi \mathrm{d}_{0}+\varphi \mathrm{d}_{1} \mathrm{x}_{\mathrm{t}-1}+\varphi \mathrm{d}_{2} \mathrm{X}_{\mathrm{t}-1}^{2}+\varphi \mathrm{d}_{3} \log \left(\mathrm{E}_{\mathrm{t}-1} \lambda_{\mathrm{t}} / \mathrm{E}_{\mathrm{t}-1} \mathrm{w}_{\mathrm{t}} \alpha_{3 \mathrm{t}}\right)$ and $E_{t-1} \lambda_{t}$ can be eliminated by proxying it with $\hat{\lambda}_{t}$ $\hat{\lambda}_{\mathrm{t}}=\left(\alpha_{1 \mathrm{t}} \mathrm{p}_{\mathrm{t}}\right)-\hat{\delta}_{1}-\hat{\delta}_{2}\left(\alpha_{2 \mathrm{t}} \mathrm{q}_{\mathrm{t}} / \mathrm{z}_{\mathrm{t}-1}\right)$ which represents the shadow price of oil in the ground and whose value is determined by using the parameter estimates from the production equation.

The estimable equation will then be $\log \mathrm{x}_{\mathrm{t}}=(1-\varphi) \log \mathrm{x}_{\mathrm{t}-1}+\varphi \mathrm{d}_{0}+\varphi \mathrm{d}_{1} \mathrm{x}_{\mathrm{t}-1}+\varphi \mathrm{d}_{2} \mathrm{x}_{\mathrm{t}-1}^{2}+\varphi \mathrm{a}_{3} \log \left(\hat{\lambda}_{\mathrm{t}} / \mathrm{w}_{\mathrm{t}} \alpha_{3 \mathrm{t}}\right)+\mathrm{u}_{\mathrm{t}}$ where ,under the REH, the disturbances $u_{t}$ satisfy the orthogonality condition $E\left(u_{t} \mid \Omega_{t-1}\right)=$ 0 . 


\section{THE EMPIRICAL RESULTS}

Our empirical analysis will focus on the sample period 1978(1)-1986(4) to allow direct comparability with the results obtained by Pesaran(1990).

\subsection{Supply Equation}

In order to estimate the Rational Expectations version of the supply equation we have to take in account the possible correlation between the composite disturbance in equation (16) and the regressors. Under the rational expectations hypothesis $\epsilon_{1 t}$ is orthogonal to the information set available at time t-1, therefore the Error in Variables procedure [McCallum(1976)] can be implemented by using instruments dated $t-1$ or earlier 4 . The Non-Linear Two Stage Least Squares method [Gallant(1987) ch.6] allows us to model the non-linearity in parameters of equation $(17)^{5}$

Possible heteroscedasticity of residuals can be taken into account by basing inference on White's(1982) heteroscedasticity consistent estimator of the covariance matrix of the instrumental variables (IV) estimators.

Following the empirical evidence provided by Mabro et al(1986) we have included seasonal dummies in the estimated equation and, in order to ensure that the seasonal effect add up to zero over a given year, we used $s_{i t}-s_{4 t} i=1,2,3$ as seasonal variables, where $s_{i t}=1$ in the $i^{\text {th }}$ quarter and zero elsewhere. The instrumental variables used are seasonal dummies, $q_{t-2}$, $\mathrm{p}_{\mathrm{t}-2}, \mathrm{~h}_{\mathrm{t}-2}, \mathrm{R}_{\mathrm{t}-2}, \mathrm{R}_{\mathrm{t}-2}^{2}, \mathrm{R}_{\mathrm{t}-2} \mathrm{q}_{\mathrm{t}-2}, \alpha_{1 \mathrm{t}-2}, \alpha_{2 \mathrm{t}-2}, \Delta \alpha_{1 \mathrm{t}-2}, \Delta \alpha_{2 \mathrm{t}-2}$, which all satisfy the orthogonality condition. The estimates of the structural parameters are reported in table 1 together with the heteroscedasticity corrected standard errors. All the estimates have the expected signs although $\delta_{1}, \delta_{2}, \delta_{3}$ are poorly determined and $\delta_{1}$ is very far from being significant.In the reported specification $\delta_{1}$ has been set to zero but the uncertainty on $\delta_{2}$ and $\delta_{3}$ remains high. The point estimate of the discount factor $\beta$ is outside the admissible range, although the hypothesis that $\beta=.9$ cannot be rejected statistically.

\footnotetext{
4In practice however we found, unexpectedly, first order serial correlation in the residuals and we have used instruments dated $t-2$ and earlier

${ }^{5}$ Notice however that the high degree of non-linearity does not allow to check the conditions for identification of parameters and the orthogonality between instruments and residuals is only a necessary condition for consistency of the resultant estimators[see Pesaran(1987)Ch.7]
} 
The adaptive expectations equation fits worse than the $\mathrm{REH}$ version and the $\mathrm{t}-$ statistics on all the parameters estimates are lower. As in Pesaran(1990) we find heteroscedasticity and autocorrelation in the residuals, more importantly the marginal extraction costs implied by the estimated parameters in equation (16) and (17), plotted in figure 7, although smaller than those obtained in the model without taxation, are still too high to be taken seriously. As in Pesaran(1990), we find empirically a negative relation between the discount factor and plausibility of the marginal extraction cost. We therefore re-estimated the two alternative models under the hypothesis that $\beta=0$. The results are reported in table 2 . We notice that both the serial correlation and the heteroscedasticity problems disappear. The REH equation is preferable to the AEH equation according to all the reported criteria. The marginal extraction costs derived from the parameters estimates (figure 8) under the RE hypothesis ( $\beta=0, \delta_{2}=.0108, \delta_{3}=21.64$ ) range from $\$ 1.04$ to $\$ 3.66$ in a perfectly acceptable region. On the basis of our results we can draw the conclusion that the most satisfactory model of oil supply in the UKCS supports the hypothesis of rational expectations with a discount factor of zero. The explicit inclusion of taxation in the intertemporal model does not modify the result obtained by Pesaran(1990) that the future is not relevant to today's oil supply decision. The main modification regards the marginal costs of extraction, which range between $\$ 1.04$ and $\$ 3.66$ in the model with taxes, and between $\$ 2.19$ and $\$ 17.25$ in Pesaran's original model over the sample period.

From the economic point of view the result of a zero discount factor can be justified as an outcome of the high degree of uncertainty, generated both by price instability and the unpredictability of a non-stable and non-neutral tax-system: in a continuously changing environment the representative firm has a very short time-horizon in choosing the determinants of its productions because predictions more than one-period ahead are not reliable. In the context of the North Sea these economic considerations are strenghtened by the technical cost of production: once a platform has been installed the high rate depreciation of capital and the prospective final cost of removal are important technical factors in reducing the sensitivity of production to future, highly unpredictable, economic factors. On the basis of this evidence the first item on the research agenda is the incorporation of a "development stage" in the optimization framework. 
The separation of overall cost function $C\left(q_{t}, R_{t-1}\right)$ in its two components,operating costs and development cost, and including the rate of development in the decision variables of the firms will allow the model to capture explicitly the dependence of the production stage on the development stage.

\subsection{The Exploration Equation}

In our theoretical model exploration is strictly linked to production through the shadow price of oil in the ground. The pre-tax and post-tax shadow prices of oil in the ground are plotted in figure 9. We notice that the pre-tax shadow price of oil in the ground is always positive while the post-tax price of oil in the ground becomes negative for the four quarters in 1986, which suggests that we are somewhat overestimating the impact of taxation towards the end of the sample. This is probably because most of the latest innovations in the $\operatorname{tax}$ system are oriented towards new fields, and there have been reductions in post-tax development cost, neither aspect is captured in our aggregate model. This evidence confirms the value of extending the model to include explicitly the development stage.

When the post-tax shadow price of oil in the ground is used to estimate the exploration equation over the sample 1978-1 1985:4 the following results are obtained

$$
\begin{aligned}
& \left.\log x_{t}=\underset{(.082)}{.46 \log x_{t-1}}+\underset{(1.25)}{1.82+.0024)} x_{t-1}^{.007} x_{\left(10^{-6} \times 1.5\right)} x_{t-1}^{-6}+\underset{(.05)}{.10} \log \left(\hat{\lambda}_{t}\right) \underset{(.08)}{-.22 \log \left(w_{t}\right.} \alpha_{3 t}\right) \\
& \mathrm{R}^{2}=.95 \quad \sigma=.09 \quad \mathrm{X}_{\mathrm{SC}}^{2}(4)=4.13 \quad \mathrm{X}_{\mathrm{FF}}^{2}(1)=.006 \mathrm{X}_{\mathrm{N}}^{2}(2)=1.08 \quad \mathrm{X}_{\mathrm{H}}^{2}(1)=3.26
\end{aligned}
$$

The model is estimated by Two Stage Least Squares $\left(\hat{\lambda}_{t}=\alpha_{1 t} \mathrm{p}_{t}-\alpha_{2 t} .0108 \hat{\mathrm{q}}_{\mathrm{t}} / \mathrm{z}_{\mathrm{t}-1}, \hat{\mathrm{q}}_{\mathrm{t}}\right.$ are the estimated values from the supply equation) once again under the maintained hypothesis $\beta=0$, standard errors are reported within brackets.

We notice that all the coefficients have the expected signs, although the restrictions that the coefficent on $\log \lambda_{t}$ and $\log \left(w_{t} \alpha_{3 t}\right)$ are equal with opposite sign is rejected by the data. The model passes all the diagnostics and the threshold value of cumulative level of exploration effort implied by the estimates is of 934 wells which in statistical terms does not support the strong implication, reached in the model without taxes, that a discovery decline 
phenomenon has already begun. ${ }^{6}$

\section{CONCLUSIONS}

The inclusion of taxation in an intertemporal econometric model of oil exploration and extraction in the UKCS reinforced the results obtained in the Pesaran(1990) model without taxes that the model implies a very short time horizon in the decision on the optimal supply, delivering much more plausible estimates of the marginal extraction costs. When the estimated marginal extraction costs are used to determine the shadow price of oil in the ground and to estimate the exploration equation, results consistent both with the theory and the recent empirical evidence in the UKCS are obtained. However the post-tax shadow price of oil in the ground becomes negative for the last four observations in our sample, suggesting that the model is overstating the impact of taxation on profit. This feature can be explained by the inability of the model to capture recent modifications in taxation aimed at helping development. The disaggregation of the model in three equations for exploration, development and production is on the agenda for future research.

${ }^{6}$ In the Pesaran(1989) model the estimate of the threshold level is 894 , while the cumulative number of exploration wells reached the figure of 943 wells in 1984 . 
TABLE 1

Estimates of the Oil supply function

Under Alternative Price Expectations Formation Models ${ }^{*}$

1978:1-1986:4

$\begin{array}{ccc}\text { Parameters } & \begin{array}{c}\text { Equa tion 16 } \\ \text { REH }\end{array} & \begin{array}{c}\text { Equa t i on 17 } \\ \text { AEH }\end{array} \\ \hat{\varphi} & .368 & .377 \\ \hat{\delta}_{2} & (.129) & (.128) \\ \hat{\delta}_{3} & .116 & .32 \\ \hat{\beta} & (.171) & (3.61) \\ \hat{\theta} & 99.57 & 417 \\ \sigma & (339.1) & (4577) \\ \mu & 1.19 & 1.11 \\ \mathrm{X}_{\mathrm{SC}}^{2}(4) & (.40) & (.21) \\ \mathrm{X}_{\mathrm{FF}}^{2}(1) & - & .96 \\ \mathrm{X}_{\mathrm{N}}^{2}(2) & 9.01 & 9.24 \\ \mathrm{X}_{\mathrm{H}}^{2}(1) & 186.78 & 186.78 \\ & 17.97 & 17.86 \\ & .62 & .87 \\ & .37 & .59 \\ & 11.09 & 12.53\end{array}$

The figures in () are the White's(1982) heteroscedasticity-consistent estimates adjusted for the degrees of freedom, $\hat{\sigma}$ is the estimated standard error of the regression, $\mu$ is the mean of the dependent variable $\mathrm{x}_{\mathrm{SC}}^{2}(4), \mathrm{x}_{\mathrm{FF}}^{2}(1), \mathrm{x}_{\mathrm{N}}^{2}(2), \mathrm{x}_{\mathrm{H}}^{2}(1)$ are diagnostic statistics distributed approximately as chi-squared variables (with the degrees of freedom reported in parentheses) for tests for residual serial correlation (up to the fourth order), functional misspecification form, non-normal errors and heteroscedasticity respectively. See Pesaran and Pesaran(1989)

*Estimation by Non linear Two-stage Least Squares computed using seasonal dummies, $q_{t-2}, p_{t-2}, h_{t-2}$, $\mathrm{R}_{\mathrm{t}-2}, \mathrm{R}_{\mathrm{t}-2}^{2}, \mathrm{R}_{\mathrm{t}-2} \mathrm{q}_{\mathrm{t}-2}, \alpha_{1 \mathrm{t}-2}, \alpha_{2 \mathrm{t}-2}, \Delta \alpha_{1 \mathrm{t}-2}, \Delta \alpha_{2 \mathrm{t}-2}$ as instruments.

The results are obtained by assuming $\gamma=\delta_{3} / \delta_{2}=2000$, which results from a grid search on the parameters.

The value of .96 reported for the adaptive expectations coefficient $\theta$ is the maximum likelihood estimate of $\theta$ computed by grid search method over the range $0 \leq \theta \leq 1$ 
TABLE 2

Estimates of the Oil supply function with zero discount factor $(\beta=0)$ Under Alternative Price Expectations Formation Models

\begin{tabular}{|c|c|c|c|}
\hline \multirow[b]{2}{*}{ Regressors } & \multicolumn{2}{|c|}{ 1978:1 } & \multirow[b]{2}{*}{$\begin{array}{l}\text { Combined } \\
\text { Model }\end{array}$} \\
\hline & $\underset{\text { REH }}{\text { Equation } 16^{*}}$ & $\begin{array}{c}\text { Equa } t \text { i on } 17^{* *} \\
\text { AEH }\end{array}$ & \\
\hline$s_{1 t}-s_{4 t}$ & $\begin{array}{l}.107 \\
(2.97)\end{array}$ & $\begin{array}{l}.286 \\
(3.21)\end{array}$ & $\begin{array}{c}.308 \\
(3.06)\end{array}$ \\
\hline$s_{2 t}$ & $\begin{array}{l}-6.15 \\
(2.96)\end{array}$ & $\begin{array}{l}-6.19 \\
(3.19)\end{array}$ & $\begin{array}{l}-6.19 \\
(3.04)\end{array}$ \\
\hline$s_{3 t}-s_{4 t}$ & $\begin{array}{l}1.35 \\
(2.96)\end{array}$ & $\begin{array}{l}1.09 \\
(3.21)\end{array}$ & $\begin{array}{l}1.24 \\
(3.04)\end{array}$ \\
\hline $\mathrm{q}_{\mathrm{t}}$ & $\begin{array}{l}.95 \\
(.027\end{array}$ & $\begin{array}{l}.96 \\
(.04)\end{array}$ & $\begin{array}{l}.92 \\
(.04)\end{array}$ \\
\hline$z_{t-1}\left(\frac{\alpha_{2 t+1}}{\alpha_{2 t}} p_{t}\right)$ & $\begin{array}{l}4.62 \\
(1.80)\end{array}$ & - & $\begin{array}{l}4.98 \\
(1.94)\end{array}$ \\
\hline $\mathrm{z}_{\mathrm{t}-1} \frac{\left.\alpha^{\alpha \mathrm{t}+1} \tilde{\mathrm{p}}(.96)\right]}{\alpha_{2 \mathrm{t}}}$ & - & $\begin{array}{l}4.28 \\
(4.03)\end{array}$ & $\begin{array}{l}1.67 \\
(3.73)\end{array}$ \\
\hline$\sigma$ & $\begin{array}{l}10.28 \\
186.78\end{array}$ & $\begin{array}{l}11.05 \\
186.78\end{array}$ & $\begin{array}{l}10.52 \\
186.78\end{array}$ \\
\hline $\mathrm{X}_{\mathrm{SC}}^{2}(4)$ & 1.01 & 2.28 & .88 \\
\hline $\mathrm{X}_{\mathrm{FF}}^{2}(1)$ & 1.73 & 7.21 & 1.06 \\
\hline $\mathrm{X}_{\mathrm{N}}^{2}(2)$ & .64 & 1.02 & .53 \\
\hline $\mathrm{X}_{\mathrm{H}}^{2}(1)$ & .15 & 1.25 & .21 \\
\hline Sargan $\mathrm{X}^{2}$ & $7.48(8)$ & $10.05(4)$ & $6.05(8)$ \\
\hline
\end{tabular}

The figures in () are the White's(1982) heteroscedasticity-consistent estimates adjusted for the degrees of freedom, $\hat{\sigma}$ is the estimated standard error of the regression, $\mu$ is the mean of the dependent variable $\mathrm{X}_{\mathrm{SC}}^{2}(4), \mathrm{x}_{\mathrm{FF}}^{2}(1), \mathrm{X}_{\mathrm{N}}^{2}(2), \mathrm{x}_{\mathrm{H}}^{2}(1)$ are diagnostic statistics distributed approximately as chi-squared variables (with the degrees of freedom reported in parentheses) for tests for residual serial correlation (up to the fourth order), functional misspecification form, non-normal errors and heteroscedasticity respectively. Sargan $\mathrm{X}^{2}$ is a test for the validity of instruments (degrees of freedom within brackets). See Pesaran and Pesaran(1989)

* Estimation by Instrumental Variables computed using seasonal dummies, $q_{t-1}, q_{t-2}, p_{t-2}, h_{t-2}, R_{t-2}$, $\mathbf{R}_{t-2}^{2}, \mathbf{R}_{t-2} \mathrm{q}_{\mathrm{t}-2}, \alpha_{1 \mathrm{t}-2}, \alpha_{2 t-2}, \Delta \alpha_{1 \mathrm{t}-2}, \Delta \alpha_{2 \mathrm{t}-2}$ as instruments.

** Estimation by Instrumental Variables computed using seasonal dummies, $q_{t-1}, \alpha_{1 t-2}, \alpha_{2 t-2}, \Delta \alpha_{1 t-2}$, $\Delta \alpha_{2 t-2}$ as instruments. 


\section{Data Appendix}

The data set used in this paper was kindly provided by Hashem Pesaran, for the definitions and sources of all the variables see the Data Appendix to Pesaran(1990). The fundamental source for the tax variables is Mabro et al.(1986), the update to the series was kindly provided by the Oxford Institute for Energy Studies. 


\section{REFERENCES}

- Clunies Ross A.I.(1982) "North Sea Oil and Gas Taxation: a case for reform" The Three Banks Review pp.32-45

- Devarajan S.,Fisher A.(1982) "Exploration and Scarcity", Journal of Political

Economy, 90, pp.1279-1290

- Eckbo P.L.,Jacoby H.D.,Smith J.(1978) "Oil Supply forecasting: a disaggregated approach" The Bell Journal of Economics 9, pp.218-235

- Epple D.N.(1985) "The econometrics of exhaustible resource supply: a theory and application " in T.Sargent(ed.) Energy, Foresight and Strategy, Resources for future, Washington

- Farzin,H.(1986) "Competition in the market for an Exhaustible Resource" JAI Press, Greenwich, Connecticut

- Erickson E., Spann R.(1971) "Supply Response in a Regulated Industry", The Bell Journal of Economics and Management Science, 2, pp. 94-121

- Fisher F.M. (1964) "Supply and costs in the U.S. Petroleum Industry: two econometric studies, The John Hopkins Press,Baltimore

- Gallant A.R.(1987) "Nonlinear Statistical Models" John Wiley, New York

- Hann D. (1985) "Political and Bureacratic Pressures on UK Oil taxation Policy" Scottish Journal of Political Economy

- Hann D., Rowland C.(1986) "UK Oil Taxation: Failings and Reform" Surrey Energy Economics Centre D.P. no.32

- Kaufman G.M.(1975) "Statistical Analysis of the Size Distribution of Oil and Gas discovery" in $\underline{\text { Studies }}$ in Petroleum Exploration No.1,AIME

- Kemp A.,D.Cohen (1980) "The Impact of the system of Petroleum Taxation in the UK on Oil Operations and Government Revenue" The Frase of Allander Institute, Research Monograph 8

- Khazzoom J.D.(1971) "The FPC Staff's econometric model of natural gas supply in the U.S." The Bell Journal of Economics and Management Sciences, 2,pp.51-93

- Jarque C.M.,Bera A.K. (1980)"Efficient Tests for Normality, Homoscedasticity and Serial Independence of Regression Residuals", Economic Letters, 5-6, pp.255-59

- Mabro et.al(1986)"The market for North Sea crude oil" Oxford University Press, Oxford

- Mazzarino G.(1987)"Databank,a Program for the Management of Time Series",Oxford, Institute of Economics and Statistics

- McCallum B.T(1976) "Rational Expectations and the estimation of econometric models:an alternative procedure" International Economic Review, 17, pp.484-490

- Pesaran M.H.(1987) "The limits to Rational Expectations", Oxford, Basil Blackwell

- Pesaran M.H.,Pesaran B.(1987) "Data-Fit: An interactive Econometric Software Package, Oxford University Press, Oxford

- Pesaran M.H.(1990) "An econometric analysis of the exploration and extraction of oil in the U.K. Continental Shelf" The Economic Journal, 100, pp.367-391 
- Pindyck R.S.(1978) "The optimal exploration and production of non-renewable resources", Journal of Political Economy, 86,pp.841-861

- Sargan J.D. (1958) "The estimation of economic relationships using Instrumental Variables" Econometrica, 26, pp.72-90

- Uhler R.S.(1976) "Costs and Supply in Petroleum Exploration: the case of Alberta", Canadian Journal of Economics,9,pp.72-90

- White H.(1982) "Maximum Likelihood Estiation of Misspecified Models" Econometrica, 50, pp.1-25 
Figure 1 PRT 1 _ Petroleum Revenue Tax

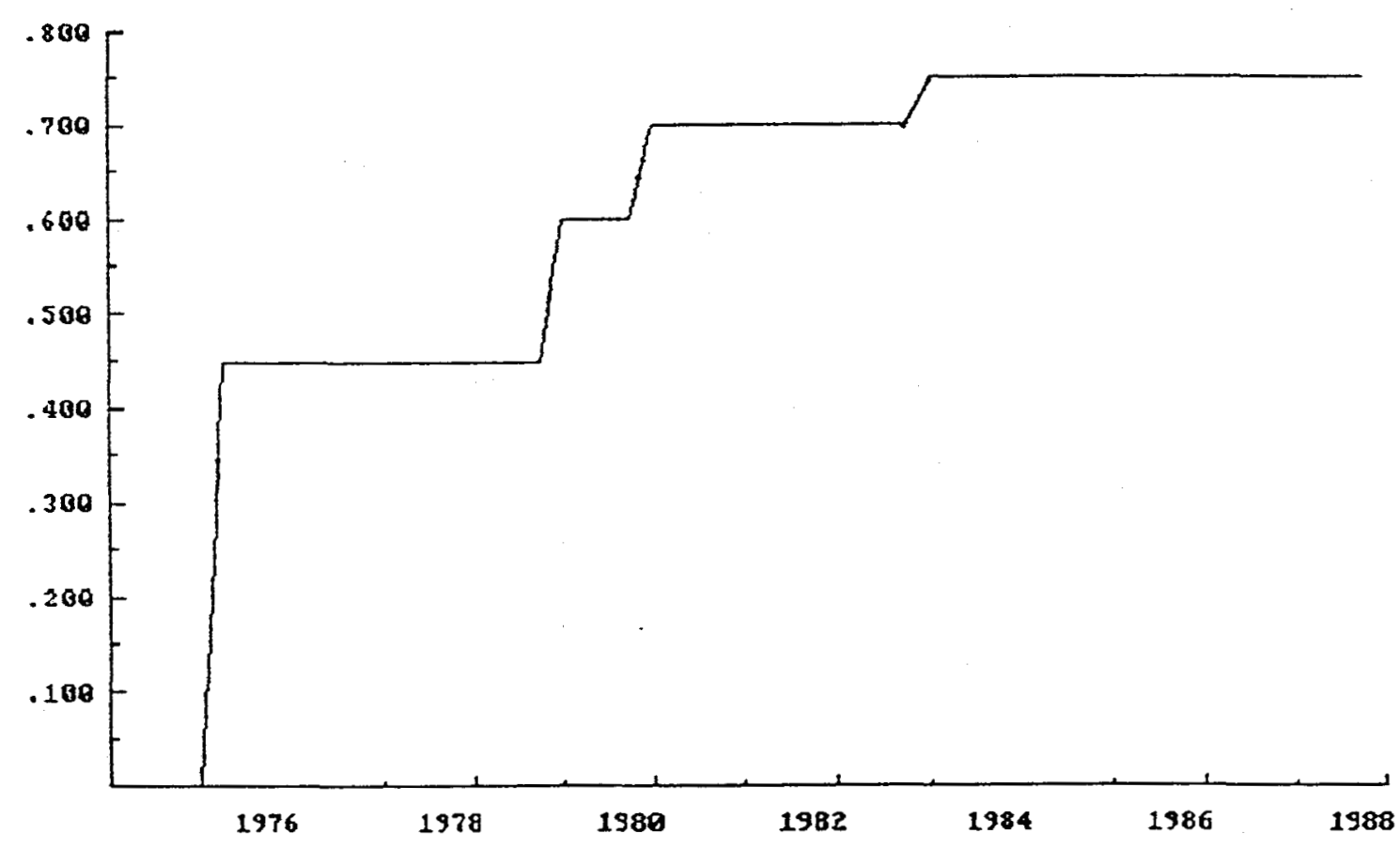


Figure 2

APBT

Advanced Petroleum Revenue Tax

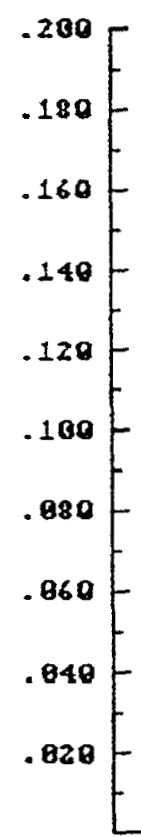

1976

1978

1980

1982

1384

1988 


\section{Figure 3}

SPD

$=$

Supplementary Petroleum Duty

.200
.180
.040
.020
.060
.1200

1976

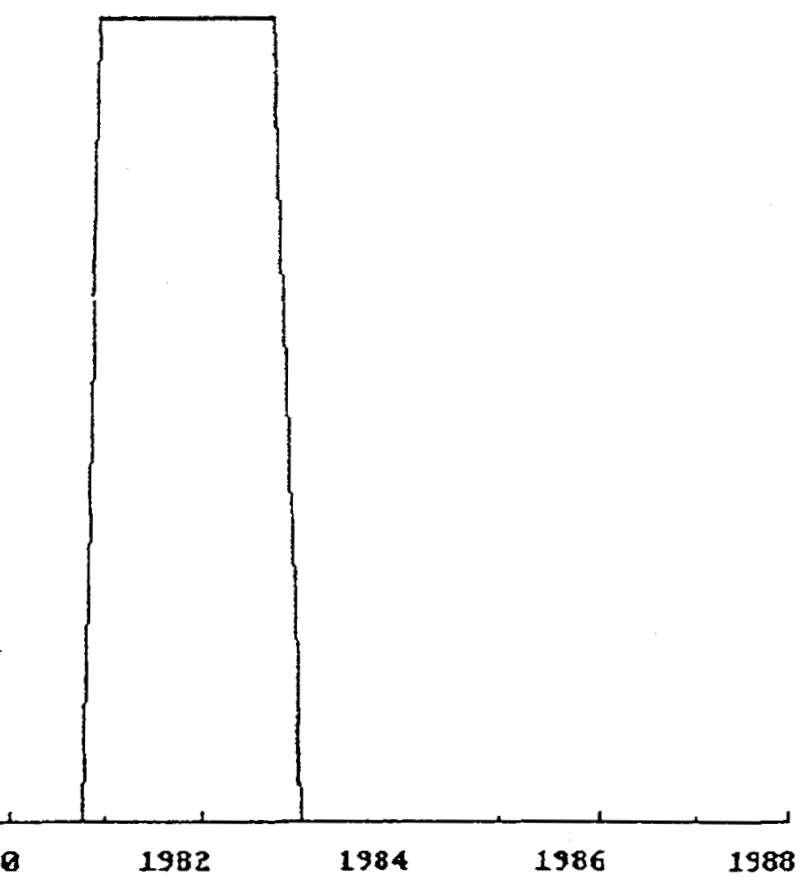




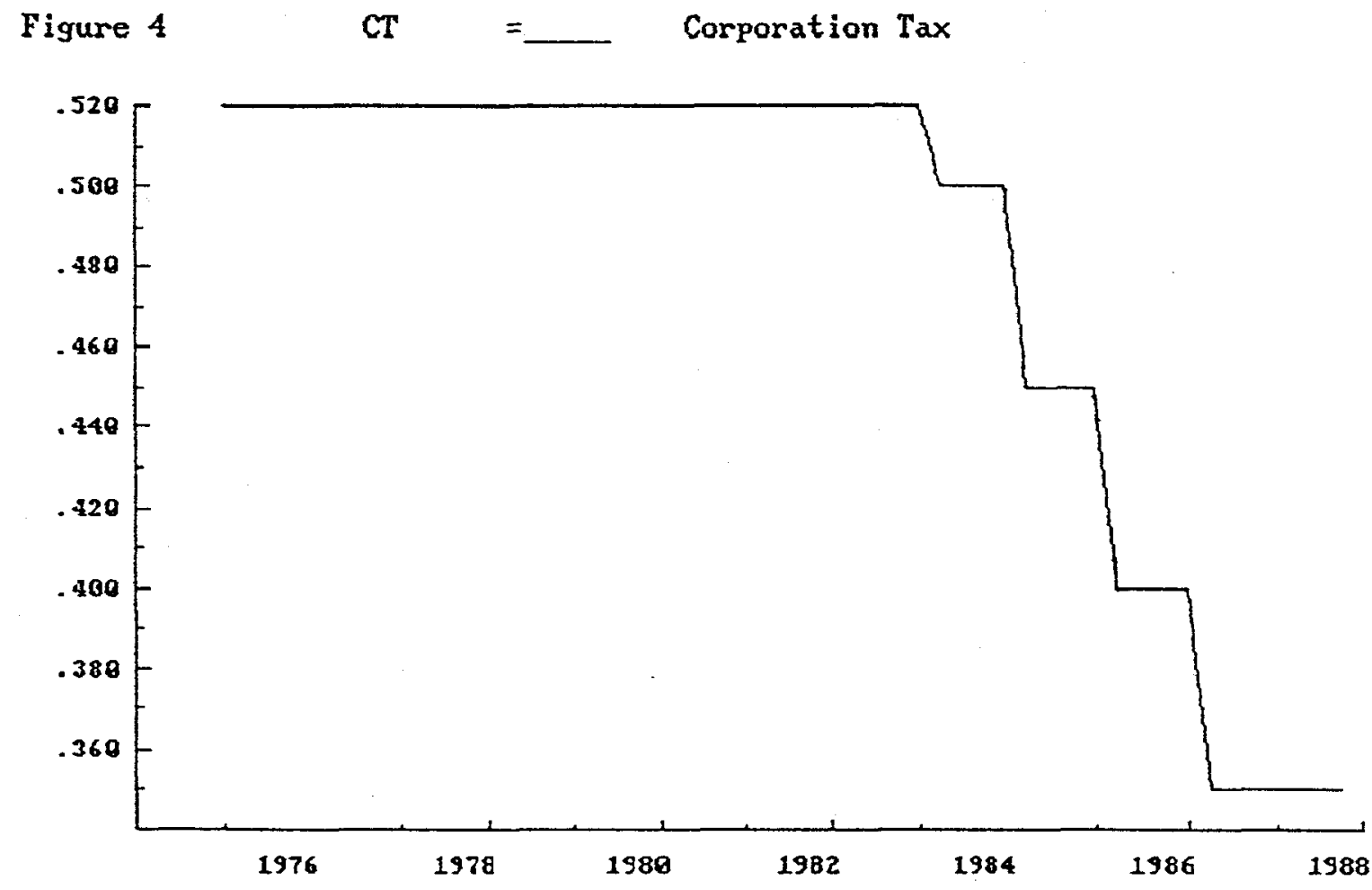


Figure 5

The Tax Variables

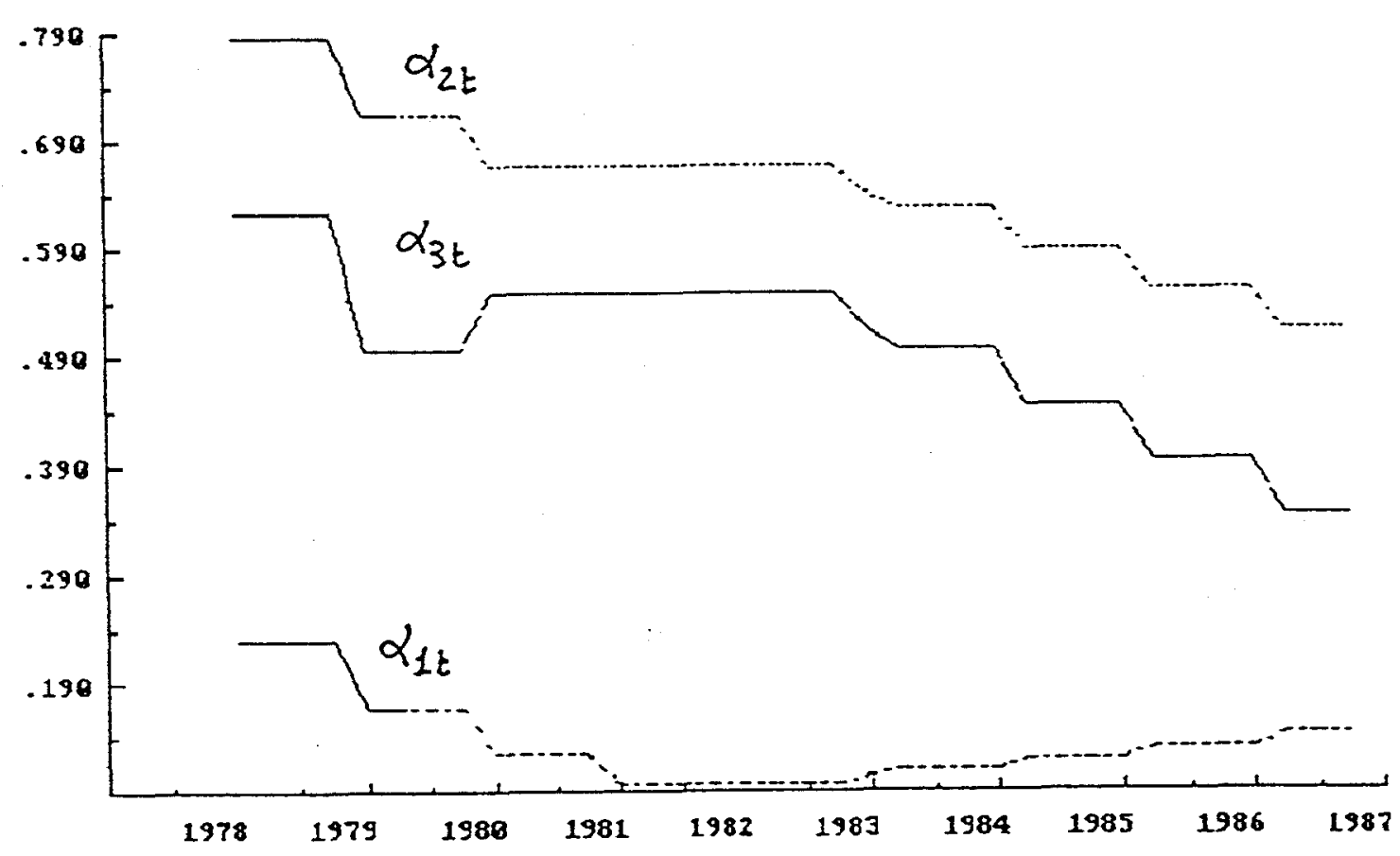


figure 6.1 The tax variables relevant to production : $\alpha_{l t} / \alpha_{2 t}$

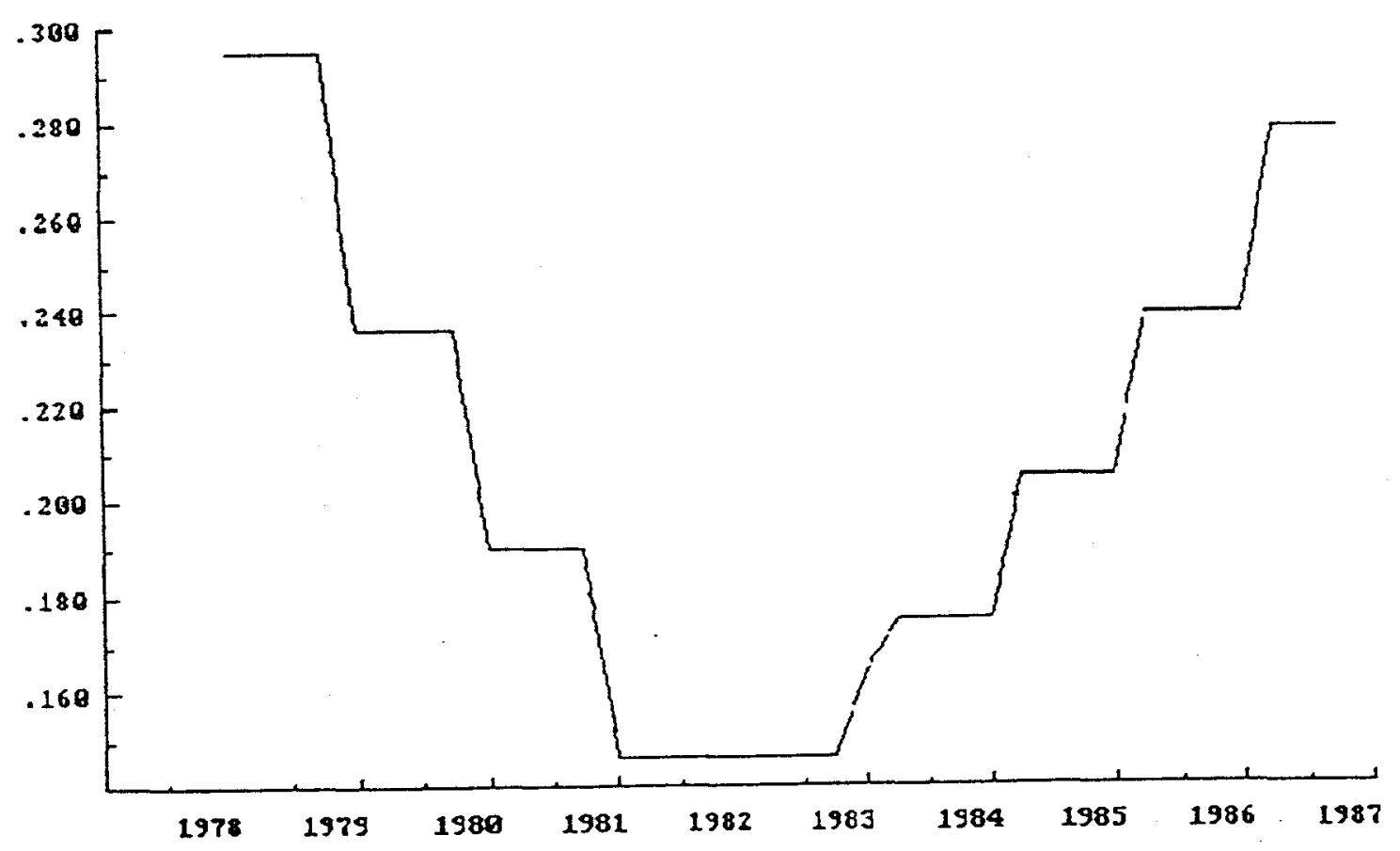


Figure 6.2 The Tax variables relevant to production $: \alpha_{1++1} / \alpha_{2 t}$

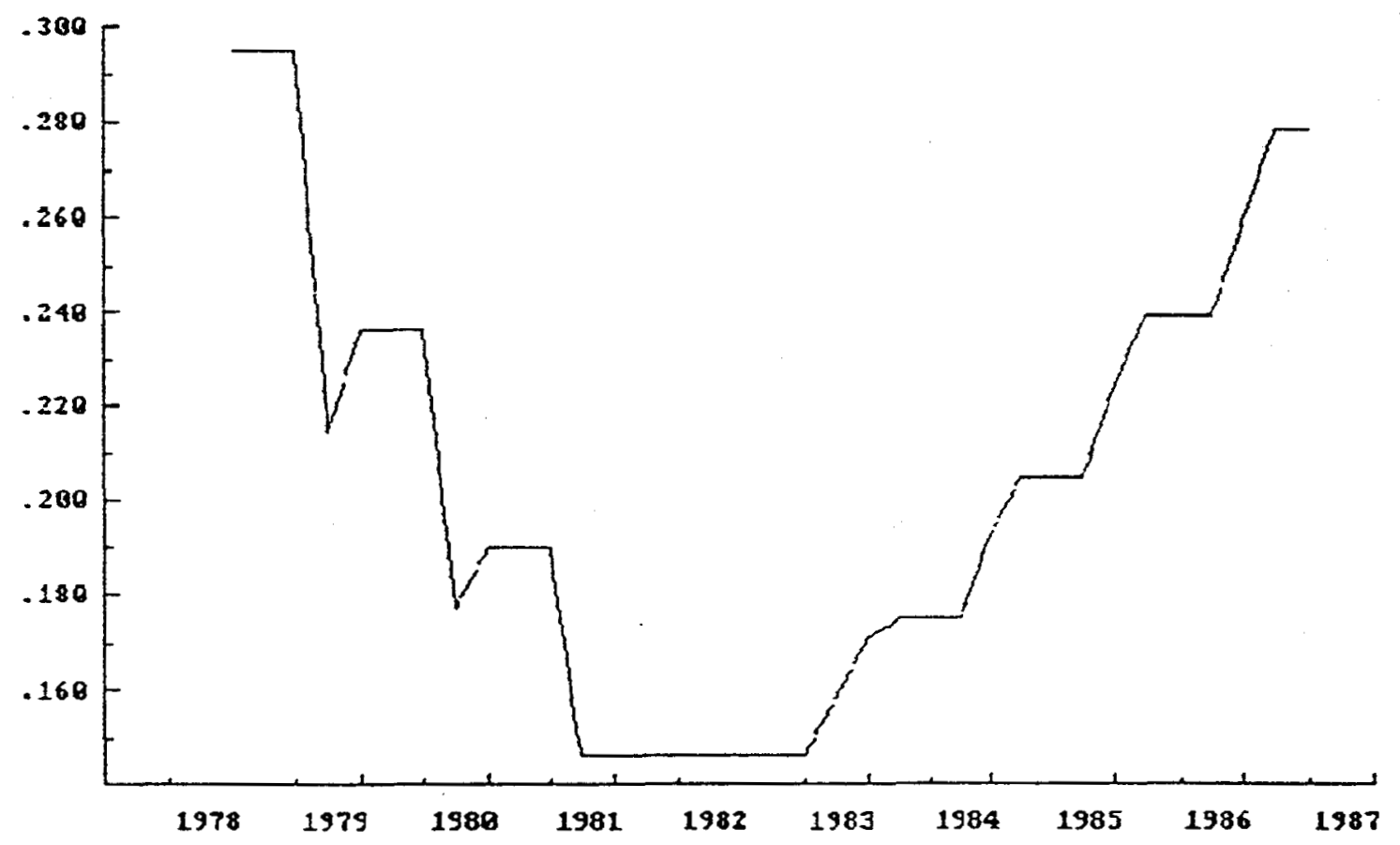


Figure 6.3 The tax variables relevant to production $: \alpha_{2 t+1} / \alpha_{2 t}$

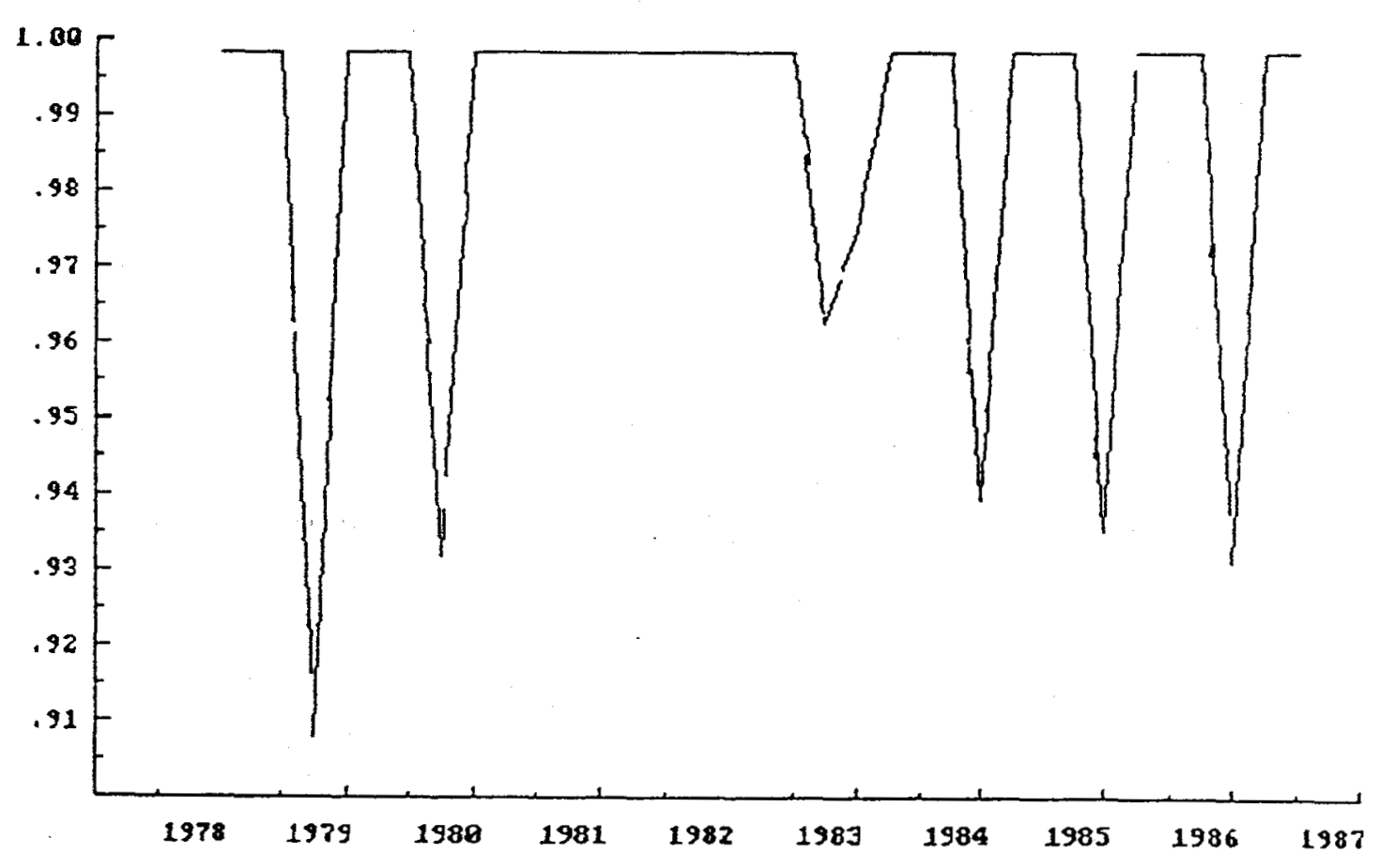


OXFORD INSTITUTE FOR ENERGY STUDIES

57 WOODSTOCK ROAD, OXFORD OX2 6FA ENGLAND

TELEPHONE (01865) 311377

FAX (01865) 310527

E-mail: publications@oxfordenergy.org

http://www.oxfordenergy.org 